\title{
Diversion colitis: histological features in the colon and rectum after defunctioning colostomy
}

\author{
J M Geraghty, I C Talbot
}

\begin{abstract}
Diversion of the faecal stream by ileostomy or colostomy leads to inflammation in the defunctioned segment, known as diversion colitis. The affected bowel is rapidly restored to normality by reanastomosis. Diversion colitis should not be mistaken for inflammatory bowel disease, for which reanastomosis would be inappropriate. Studies of biopsy material from patients with diversion colitis have shown a variety of histological features, but no consistent pattern. The histology in resection specimens of defunctioned large bowel from 15 patients with no pre-existing inflammatory bowel disease was studied. Nine patients had symptoms of abdominal pain or rectal discharge of blood or mucus that developed between 9 months and 17 years after diversion procedure. The histology was abnormal in all. Findings were similar in 14 patients, regardless of the duration of faecal diversion, and comprised diffuse mild chronic inflammation with or without mild crypt architectural abnormalities, crypt abscesses, or follicular lymphoid hyperplasia. One patient had more severe changes, resembling active ulcerative colitis. These features in biopsy specimens are unlikely to be diagnostic but should provide useful information in avoiding a mistaken diagnosis of inflammatory bowel disease in these patients.
\end{abstract}

Department of Pathology, St Mark's Hospital, City Road, London

J M Geraghty

I C Talbot

Correspondence to: Dr I C Talbot, Department of Pathology, St Mark's Hospital, City Road, London ECIV 2PS.

Accepted for publication 16 October 1990

Inflammation in defunctioned large bowel related to diversion of the faecal stream, so called diversion colitis, has been recognised only in recent years. 'A number of case reports and small series have described a variety of histological features in diversion colitis, mostly from biopsy material. ${ }^{1-11}$ These include non-specific chronic inflammation with or without crypt

TABLE I Age and sex distribution, underlying diagnosis, duration of diversion, symptoms, and details of resection specimens in 15 patients with defunctioned large bowel

\begin{tabular}{|c|c|c|c|c|c|}
\hline $\begin{array}{l}\text { Patient } \\
\text { no }\end{array}$ & $\begin{array}{l}\text { Age at } \\
\text { diversion } \\
\text { operation } \\
\text { (yrs)/sex }\end{array}$ & Underlying diagnosis & $\begin{array}{l}\text { Duration of } \\
\text { diversion } \\
\text { (mths) }\end{array}$ & Symptoms & Resection time \\
\hline 1 & $8 / \mathrm{M}$ & Hirschprung's disease & 120 & Perianal sepsis & $30 \mathrm{~cm} \mathrm{~S}+\mathrm{R}$ \\
\hline 2 & $31 / M$ & Indiopathic megacolon & 10 & Fistula & $19 \mathrm{~cm} \mathrm{~S}+\mathrm{R}$ \\
\hline 3 & $56 / \mathrm{F}$ & Idiopathic megacolon & 9 & Blood +mucus PR & $24 \mathrm{~cm} \mathrm{~S}, \mathrm{R}+\mathrm{A}$ \\
\hline 4 & $55 / \mathrm{F}$ & Perianal sepsis & 63 & Blood + mucus PR & $25 \mathrm{~cm} \mathrm{~S}+\mathrm{R}$ \\
\hline 5 & $32 / \mathrm{M}$ & Constipation (neurological) & 201 & Blood PR & $12 \mathrm{~cm} \mathrm{R}$ \\
\hline 6 & $49 / M$ & Incontinence & 12 & Mucus PR & $34 \mathrm{~cm} \mathrm{~S}+\mathrm{R}$ \\
\hline 7 & $45 / \mathrm{F}$ & Constipation & 15 & Mucus PR & $31 \mathrm{~cm} \mathrm{~S}, \mathrm{R}+\mathrm{A}$ \\
\hline 8 & $43 / \mathrm{F}$ & Incontinence & 45 & Mucus PR & $50 \mathrm{~cm} \mathrm{~S}, \mathrm{R}+\mathrm{A}$ \\
\hline 9 & $51 / F$ & Constipation & 20 & Mucus PR & $41 \mathrm{~cm} \mathrm{~S}, \mathrm{R}+\mathrm{A}$ \\
\hline 10 & $29 / \mathrm{M}$ & Idiopathic megacolon & 73 & Mucus PR & $12 \mathrm{~cm} \mathrm{R}+\mathrm{A}$ \\
\hline 11 & 2 days $/ M$ & Imperforate anus & 423 & LIF pain & $60 \mathrm{~cm} \mathrm{~S}+\mathrm{R}$ \\
\hline 12 & $45 / F$ & Constipation & 38 & None & $49 \mathrm{~cm} \mathrm{~S}, \mathrm{R}+\mathrm{A}$ \\
\hline 13 & $43 / M$ & Anal carcinoma & 6 & None & $10 \mathrm{~cm} \mathrm{R}$ \\
\hline 14 & $17 / \mathrm{F}$ & Idiopathic megacolon & 40 & None & $15 \mathrm{~cm} \mathrm{~S}$ \\
\hline 15 & $18 / M$ & Trauma & 14 & None & $15 \mathrm{~cm} \mathrm{~S}+\mathrm{R}$ \\
\hline
\end{tabular}

$\mathrm{S}=$ sigmoid colon $; \mathrm{R}=$ rectum $; \mathrm{A}=$ anus $\mathrm{PR}=$ per rectum $\mathrm{LIF}=$ left iliac fossa. abscesses, ${ }^{15-11}$ aphthous ulceration, ${ }^{37}$ and follicular lymphoid hyperplasia. ${ }^{279-11}$ However, no consistent histological pattern has emerged.

Defunctioning of the large bowel by ileostomy or colostomy is carried out in a number of conditions including Crohn's disease, faecal incontinence, idiopathic constipation, and sphincter-saving operations for large bowel cancer. Diversion colitis may develop in all cases, often within a few months. ${ }^{6}$ It is successfully treated by reanastamosis, which rapidly restores the bowel to normality. ${ }^{126810}$ It is most important that this form of colitis is not mistaken for inflammatory bowel disease, for which resection of the defunctioned segment might be the most appropriate treatment. ${ }^{26}$

The aim of this study, therefore, was to examine in detail the histological changes in resection specimens of defunctioned large bowel.

\section{Patients and methods}

Resection specimens of defunctioned distal large bowel, at least $10 \mathrm{~cm}$ and up to $60 \mathrm{~cm}$ in length, from 15 patients were studied. The series included eight men, mean age $26 \cdot 2$ years at the time of the defunctioning operation (range 2 days to 49 years), and seven women, mean age 44.5 years (range 17 to 56 years). The underlying conditions included constipation (8), incontinence (2), anal carcinoma (1), trauma (1), perianal sepsis (1), congenital imperforate anus (1), and Hirschprung's disease (1). The age and sex distribution, details of resection specimens, and clinical data are summarised in Table I. The stomas were end colostomies in all cases; no patient with a loop colostomy was admitted to the study.

At least three and up to nine blocks were sampled from each specimen, embedded in paraffin wax, and processed by standard methods. The sections were stained with haematoxylin and eosin and examined for the following features, which have been fully described before. ${ }^{12}$

(1) Mucosal crypt architecture: branching, atrophy, distortion, dilatation, and degeneration.

(2) Crypt epithelium: mucin depletion, regenerative hyperplasia, pyloric gland metaplasia, Paneth cell metaplasia, epithelial destruction, and endocrine cell hyperplasia.

(3) Inflammation: acute and chronic inflammation, ulceration, and oedema. The depth of the inflammatory infiltrate within the bowel wall, and whether this was diffuse or patchy in distribution were recorded for each section. The number of lymphoid follicles per $\mathrm{mm}$ of muscularis mucosae, the presence or absence of 
TABLE II Histological changes in resection specimens of defunctioned large bowel from 15 patients

\begin{tabular}{lr}
\hline Changes & No \\
\hline Chronic inflammation & 15 \\
Acute inflammation & 7 \\
Ulceration & 3 \\
Follicular hyperplasia & 4 \\
Crypt branching & 9 \\
Crypt atrophy & 8 \\
Crypt distortion & 12 \\
Crypt dilatation & 3 \\
Crypt degeneration & 1 \\
Mucin depletion & 3 \\
Regenerative hyperplasia & 2 \\
Paneth cell metaplasia & 3 \\
\hline
\end{tabular}

germinal centres, and the maximum diameter of the lymphoid follicles were also recorded.

Each histological parameter was graded independently by both authors as mild, moderate, or severe. Discrepancies were settled by concensus. Abnormalities of the muscularis mucosae, submucosa, muscularis propria, and serosa and miscellaneous abnormalities such as epithelioid or mucin granulomas or fibrosis were noted if present.

\section{Results}

\section{MACROSCOPIC FEATURES}

Macroscopically, the large bowel mucosa showed diffuse granularity (4), patchy mucosal congestion or punctate haemorrhage (3), or a follicular pattern (1), but the mucosa was unremarkable in seven cases. The circumference of the bowel was reduced to $4 \mathrm{~cm}$ or less in six of the specimens.

\section{HISTOLOGY}

Details of the histological findings are documented in Table II.

One patient (patient 1 in Table I) had severe diffuse histological changes resembling active ulcerative colitis (Fig 1). The features included crypt branching, atrophy and distortion, mucin depletion, regenerative hyperplasia, Paneth cell

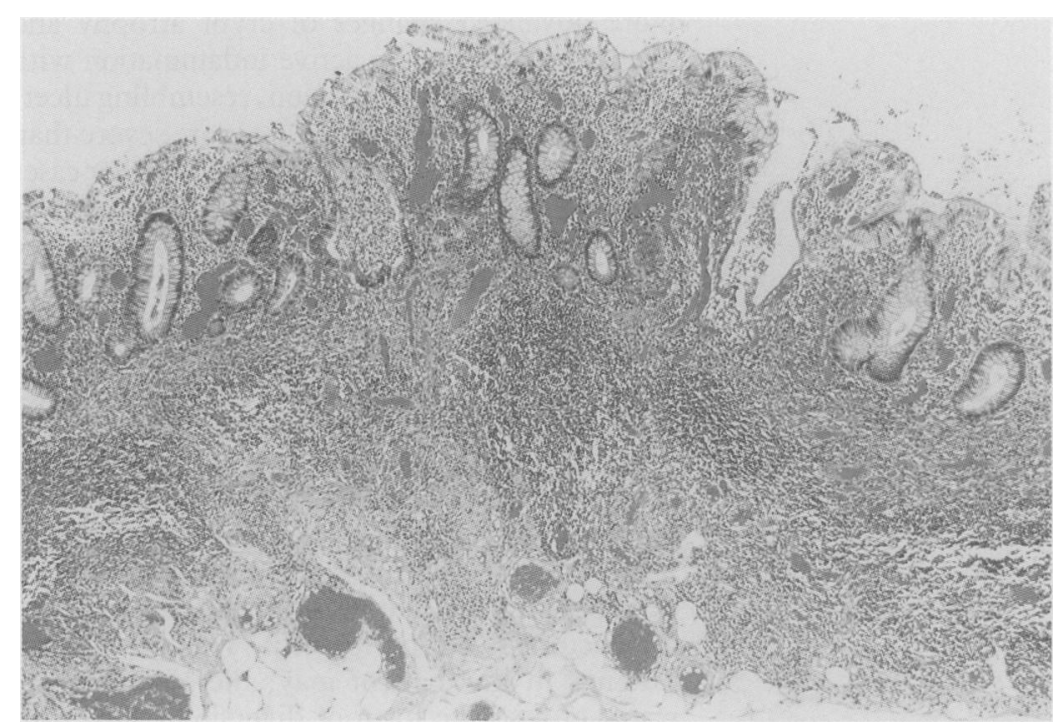

Figure 1: Rectal mucosa from patient 1 showing diffuse chronic inflammation, crypt atrophy and distortion, and numerous crypt abscesses. The surface epithelium shows vacuolar degeneration and damage. (Original magnification $\times 45$.) metaplasia, thickening and splaying of the muscularis mucosae, and diffuse active mucosal inflammation with crypt abscesses, ulceration and vacuolar degeneration, and damage of the surface epithelium. All of these features were of moderate or severe grade. No biopsy specimens have been taken from the more proximal colon since the proctosigmoidectomy in 1985 , but the patient has been reviewed regularly and has remained asymptomatic.

The changes in the remaining 14 patients were generally mild and non-specific (Fig 2). Chronic inflammation was universal, graded mild in 10 patients and moderate in four. The infiltrate was composed mainly of plasma cells with smaller numbers of lymphocytes, macrophages, and eosinophils. Chronic inflammation was usually confined to the mucosa, but was also present in the upper submucosa in two cases. Acute inflammation was present in only six patients (patients $4,5,6,7,8$, and 14 in Table I), and was always mild with scattered crypt abscesses. Crypt distortion, branching, and atrophy were common, but always of mild grade. The inflammation and crypt abnormalities were diffuse and present in all the sections examined in most cases. Three patients, however, had patchy inflammation with no regional variation, while another showed diffuse inflammation and crypt abnormalities in the distal half only of a $15 \mathrm{~cm}$ proctectomy specimen.

Crypt dilatation and degeneration, mucin depletion, regenerative hyperplasia, and Paneth cell metaplasia were uncommon and of low grade when present.

Severe follicular hyperplasia, with lymphoid follicles numbering at least $1 / \mathrm{mm}$ of muscularis mucosae, was present in the patient whose condition resembled active ulcerative colitis and in three others (patients 2, 5, and 6 in Table I). In only one patient was the pattern sufficiently well developed for a diagnosis of follicular proctitis ${ }^{13}$ (Fig 3). The lymphoid follicles had prominent germinal centres and measured up to $1.6 \mathrm{~mm}$ in maximum diameter in this patient. No aphthoid ulcers or granulomas were present in any case.

Severe ulceration was present in the patient in whom the histological changes resembled those of active ulcerative colitis, and mild ulceration in the form of surface erosions was shown in a further two (patients 5 and 15 in Table I). Focal splaying and thickening of the muscularis mucosae, suggestive of previous healed ulceration, was seen in three patients (patients 1,5 , and 10 in Table I).

\section{CORRELATION BETWEEN HISTOLOGY AND} CLINICAL PRESENTATION

The indications for resection were rectal discharge of mucus (5), blood (3), or both, perianal sepsis or fistula (2), and left iliac fossa pain (1). Defunctioned colon was removed in the other patients at the time of reanastomosis, resisting of the colostomy, or repair of a paracolostomy hernia. In general, there was poor correlation between histological findings and clinical symptoms. The patient with follicular proctitis complained of rectal discharge of blood, but lymphoid follicular hyperplasia was not present 


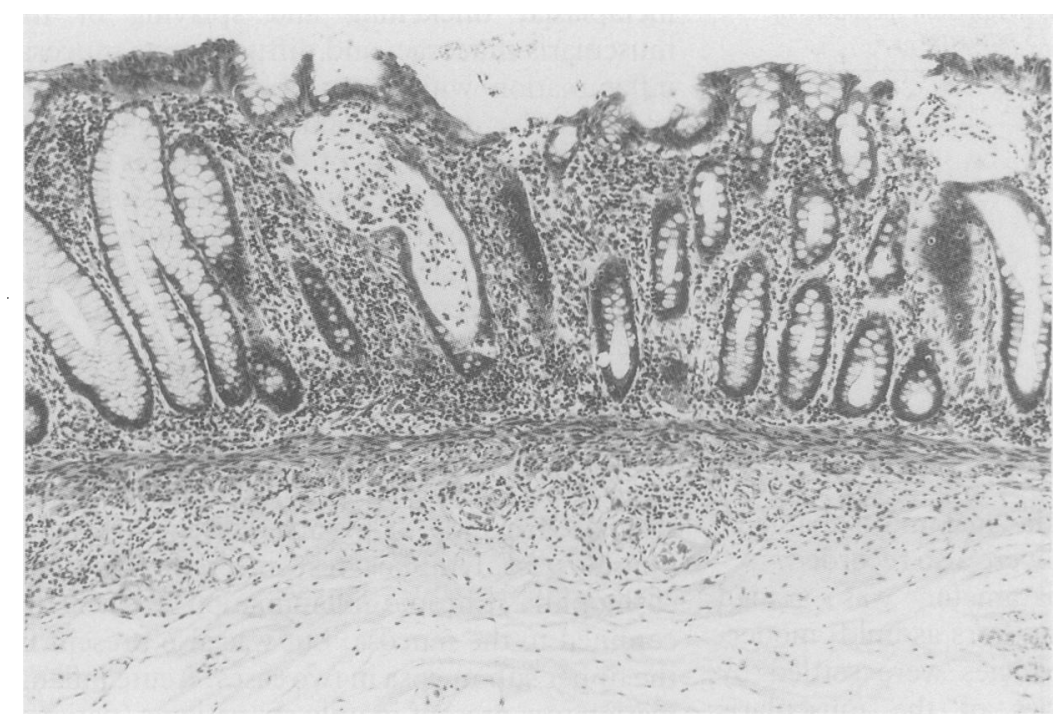

Figure 2: Sigmoid colon mucosa from patient 14 showing diffuse chronic inflammation extending slightly into the submucosa. There are scattered crypt abscesses and mild crypt distortion and bifurcation, but goblet cells are well preserved. (Original magnification $\times 45$.)

in two other patients with this symptom. The patient with the semblance of ulcerative colitis presented with perianal sepsis; other symptoms in this patient were not documented in the case notes.

The histology was remarkably similar, no matter what the clinical presentation, macroscopic findings, or duration since the diversion procedure.

\section{Discussion}

Inflammation occurring in excluded segments of large bowel was first recognised by Morson in $1972,{ }^{14}$ and subsequently labelled diversion colitis by Glotzer et al, ${ }^{1}$ who causally related the inflammation to faecal diversion. Since then a number of case reports and small series have been published, describing the histological features mainly from biopsy material. ${ }^{1-11}$ Only one previous report gave a detailed description of a resection specimen. ${ }^{7}$ The histological features described previously include aphthoid

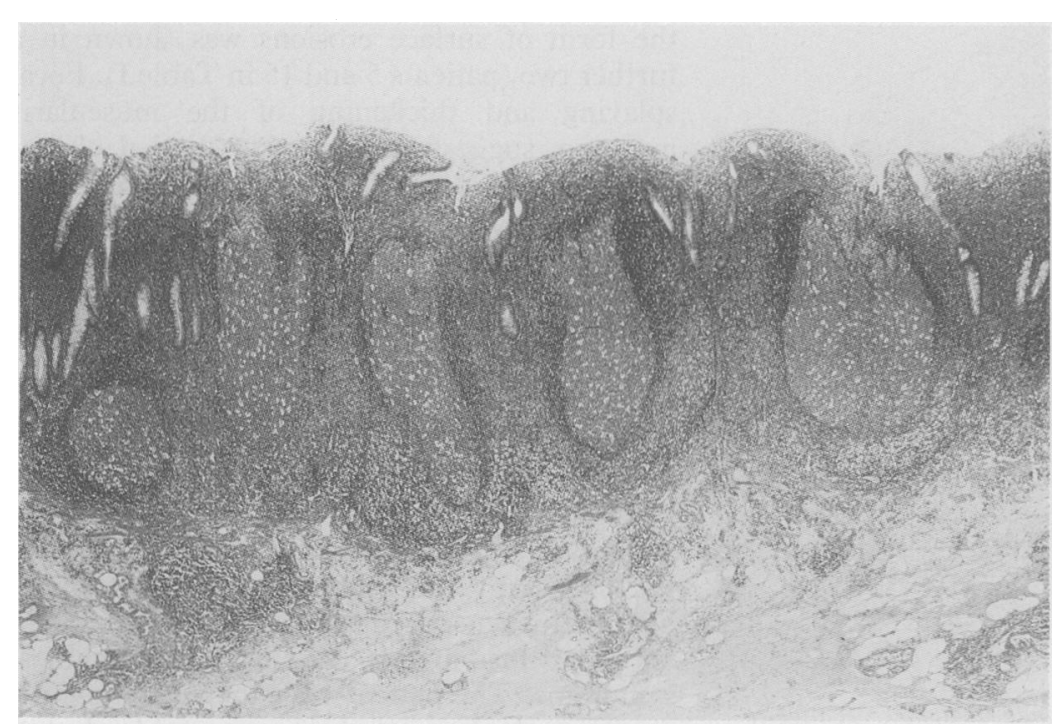

Figure 3: Rectal mucosa from patient 5 showing follicular proctitis. (Original magnification $\times 22$.) ulceration, ${ }^{37}$ follicular hyperplasia, ${ }^{279-11}$ and non-specific chronic or active inflammation, ${ }^{12+6911}$ with or without mild crypt architectural abnormalities. ${ }^{5781011}$ However, no consistent histological pattern has emerged.

Diversion colitis warrants widespread recognition among clinicians and pathologists because the inflammation subsides when bowel continuity is restored 126810 and a mistaken diagnosis of inflammatory bowel disease might lead to inappropriate treatment. This is especially pertinent in the case of patients with an established diagnosis of Crohn's disease, in whom diversion of the faecal stream is thought to improve the disease in the proximal segment. Subsequent inflammation occurring in the previously uninvolved defunctioned segment could be interpreted as recurrent Crohn's disease, perhaps leading to surgical resection rather than reanastamosis. ${ }^{26}$

This study aimed to describe the histological changes in resection specimens of defunctioned colon from patients with no primary mucosal abnormality. Some previous studies have included patients with Crohn's disease or diverticulitis, thus potentially confounding the results. ${ }^{261011}$

We have described a histological pattern in defunctioned colon comprising diffuse mild to moderate chronic inflammation, usually confined to the mucosa, with or without scattered crypt abscesses and mild crypt atrophy, branching, and distortion. The changes usually affected the entire excluded segment. Other features described in previous reports such as regenerative hyperplasia, ${ }^{10}$ mucin depletion, ${ }^{910}$ and surface erosion ${ }^{5910}$ were less common. Four of our patients had follicular lymphoid hyperplasia, a pattern described in diversion colitis by others, ${ }^{279-11}$ but in only one of these were the follicles sufficiently well developed for a diagnosis of follicular proctitis to be made. ${ }^{13}$ Aphthoid ulceration was not seen in a single case. It is worth noting that aphthoid ulceration has been confirmed histologically in only one previously reported case of diversion colitis. ${ }^{7}$

The defunctioned colon in one patient showed more advanced changes of crypt atrophy and distortion, and severe active inflammation with crypt abscesses and ulceration, resembling ulcerative colitis. These features are more severe than the relatively mild changes seen in the other cases in this study. However, Ma et al ${ }^{11}$ described histological features similar to those of ulcerative colitis in biopsy specimens from three of their 21 patients with defunctioned colon. The authors considered these findings to represent severe diversion colitis rather than ulcerative colitis because the large bowel proximal to the colostomy was endoscopically normal in each case. Endoscopic examination of the proximal segment has not been carried out in our patient because no important colonic symptoms have developed in the five years since the proctosigmoidectomy was performed. The histological findings in this patient may, therefore, be the result of a severe form of diversion colitis, but without biopsy histology of the proximal colon, ulcerative colitis cannot be entirely excluded.

Macroscopically, the mucosa showed a variety 
of appearances, but in half the cases it was unremarkable. There was no correlation between the gross appearances and the histology. Granular and follicular patterns and focal mucosal hyperaemia, present in half the patients in this series, have been described before in patients with diversion colitis. ${ }^{51115}$ Thickening of the muscularis propria and an increase in serosal fat are said to occur in defunctioned colon, ${ }^{15}$ but these were not seen histologically in this series. However, the bowel lumen was significantly reduced in six of the patients.

Only nine of the patients presented clinically with symptoms attributable to colitis - that is rectal discharge of mucus, blood, or both, or abdominal pain. These symptoms may develop at any time - from nine months to 17 years in this series. Others have shown that symptomatic colitis may develop within a few months of the diversion procedure. ${ }^{611}$ Although symptoms associated with diversion colitis are well documented, ${ }^{+57811}$ it is thought that many patients are asymptomatic and therefore escape clinical detection. ${ }^{911}$ Some degree of inflammation was present in all our patients, even in those without symptoms, and may therefore be a universal phenomonen in defunctioned large bowel. ${ }^{6}$

It is curious that the histological findings were similar, regardless of symptoms or of the duration of faecal diversion. This is in contrast to the findings of Mingazzini et al, ${ }^{8}$ who documented histological progression from active non-specific inflammation to a 'burnt out' atrophic picture over many years. Symptoms of mucous discharge per rectum were present only in the early stages. One patient in the present series who presented with rectal discharge of blood had follicular proctitis, but this was not present in the two other patients with this symptom. However, a syndrome of rectal bleeding associated with follicular proctitis unrelated to defunctioning has been reported. ${ }^{13}$

Current research into the aetiology of diversion colitis focuses on the role of trophic factors present in faeces, notably short chain fatty acids. ${ }^{9}$ The fatty acids are produced by anaerobic bacteria, which are known to be present in reduced numbers in excluded colon. ${ }^{16}$ In vitro studies have shown that butyric acid acts preferentially as a respiratory fuel in human colonocytes. ${ }^{17}$ Local administration of short chain fatty acids in similar concentration to that in faeces was associated with a reduction in the inflammation, judged endoscopically and histologically, in a recent study on four patients with diversion colitis. ${ }^{9}$

The histological resemblance of some cases of diversion colitis to active ulcerative colitis suggests a possible pathogenetic link between the two diseases. In support of this hypothesis, interference with colonocyte metabolism by inhibitors of fatty acid oxidation has been proposed as an initiating event in ulcerative colitis, ${ }^{18}$ based on experimental studies. ${ }^{19}$

In conclusion, we have described a spectrum of histological changes in defunctioned colon. The most common pattern is a diffuse nonspecific chronic proctitis or colitis with or without mild crypt architectural abnormalities, crypt abscesses, or follicular lymphoid hyperplasia. A more severe pattern, similar to that seen in ulcerative colitis, may be encountered, but this is uncommon. These features are unlikely to be diagnostic in biopsy specimens, but should provide useful information in the correct clinical setting.

1 Glotzer DJ, Glick ME, Goldman H. Proctitis and colitis following diversion of the fecal stream. Gastroenterology following diversion

2 Korelitz BI, Cheskin LJ, Sohn N, Sommers SC. Proctitis after fecal diversion in Crohn's disease and its elimination with reanastamosis: implications for surgical management. Gastroenterology 1984; 87: 710-3.

3 Lusk LB, Reichen J, Levine JS. Aphthous ulceration in diversion colitis: clinical implications. Gastroenterology 1984 87: 1171-3.

4 Bosshardt RT, Abel ME. Proctitis following fecal diversion. Dis Colon Rectum 1984; 27: 605-7.

5 Ona FV, Boger JN. Rectal bleeding due to diversion colitis. Am f Gastroenterol 1985; 80: 40-1.

6 Korelitz BI, Cheskin LJ, Sohn N, Sommers SC. The fate of the rectal segment after diversion of the fecal stream in Crohn's disease: its implications for surgical management f Clin Gastroenterol 1985; 7: 37-43.

7 Murray FE, O'Brien MJ, Birkett DH, Kennedy SM, LaMon JT. Diversion colitis: pathologic findings in a resected sigmoid colon and rectum. Gastroenterology 1987; 93: 1404-8.

8 Mingazzini PL, Giuliani A, Caporale A, Alessi G, Tocchi A, Teneriello F. Defunctioned colon. Clinical, endoscopical, radiological and histopathological observations. Ital $\mathcal{f}$ Gastroenterol 1987; 19: 329-33.

9 Harig JM. Soergel KH, Komorowski RA, Wood CM. Treatment of diversion colitis with short-chain fatty acid irrigament of diversion colitis with short-ch
tion. N Engl F Med 1989; 320: 23-8.

10 Komorowski RA. Histologic spectrum of diversion colitis. Am f Surg Pathol 1990; 14: 548-54.

11 Ma CK, Gottlieb C, Haas PA. Diversion colitis: a clinicopathologic study of 21 cases. Hum Pathol 1990; 21: 429-36.

12 Talbot IC, Price AB. Biopsy pathology in colorectal disease. London: Chapman and Hall, 1987: 19-79.

13 Flejou JF, Potet F, Bogomoletz WV, Rigaud C, Fenzy A, Le Quintrec Y, et al. Lymphoid follicular proctitis. A condition different from ulcerative proctitis? Dig Dis Sci 1988; 33: 314-20.

14 Morson BC, Dawson IMP. Gastrointestinal pathology. 1st ed. London: Blackwell, 1972: 485.

15 Morson BC, Dawson IMP, Day DW, Jass JR, Price AB Williams GT. Morson and Dawson's Gastrointestinal pathology. 3rd ed. London: Blackwell, 1990: 529-30.

16 Neut C, Colombel JF, Guillemot F, Cortot A, Gower P Quandalle $\mathrm{P}$, et al. Impaired bacterial flora in human excluded colon. Gut 1989; 30: 1094-8.

17 Roediger WE. Role of anaerobic bacteria in the metabolic welfare of the colonic mucosa in man. Gut 1980; 21: 793-8.

18 Roediger WE. What sequence of pathogenetic events leads to acute ulcerative colitis? Dis Colon Rectum 1988; 31: 482-7.

19 Roediger WE, Nance S. Metabolic induction of experimental ulcerative colitis by inhibition of fatty acid oxidation. $\mathrm{Br} \mathcal{F}$ Exp Pathol 1986; 67: 773-82. 